\title{
Presence of Escherichia coli, Trueperella pyogenes, a-hemolytic streptococci, and coagulase-negative staphylococci and prevalence of subclinical endometritis
}

\author{
A. Sens and W. Heuwieser ${ }^{1}$ \\ Clinic for Animal Reproduction, Freie Universität Berlin, 14163 Berlin, Germany
}

\begin{abstract}
Subclinical endometritis (SCE) has a severe negative effect on reproductive performance of dairy cows. Different studies have shown a wide variety of cut points for the polymorphonuclear neutrophilic leukocyte (PMNL) percentage to define SCE and differing sampling times. Possible risk factors for SCE, such as low body condition score, hyperketonemia, and increased haptoglobin concentrations have been demonstrated. The aim of this study was to determine the relationship between bacterial findings in the uterus and PMNL in the early postpartum period and to compare 2 classification schemes for the diagnosis of SCE. Cytological and bacteriological samples from the uterus were taken from 149 cows at 2 consecutive times postpartum [10 \pm 1 and $24 \pm 1 \mathrm{~d}$ in milk (DIM)] and additionally, 131 cows were sampled at 21 to 27 DIM. For sample collection, the cytobrush technique was used and vaginal discharge was examined by vaginoscopy. Polymorphonuclear neutrophilic leukocyte cut points were set at 5,10 , and $18 \%$. Cows positive with $\alpha$-hemolytic streptococci at $10 \pm 1$ DIM had significant higher PMNL percentages at 21 to 27 DIM and greater median days to pregnancy $(193.5 \mathrm{~d})$ than cows not infected (123.0 d). Cows with Trueperella pyogenes at $10 \pm 1$ DIM had higher odds (5.2) of having more than 18\% PMNL at 21 to 27 DIM compared with cows without infection. Escherichia coli had no effect on the prevalence of SCE regardless of the cut point. Primiparous cows with more than $18 \%$ PMNL had greater median days to pregnancy $(144.5 \mathrm{~d})$ than cows with less than $5 \%$ (80.0 d) or cows between 5 and 18\% PMNL (68.0 d). Cows between 5 and 18\% PMNL or 10 and 18\% PMNL showed the best reproductive performance. The results demonstrate that an early infection with $\alpha$-hemolytic streptococci increased the PMNL percentage 2 wk later and that $18 \%$ PMNL at 21 to 27 DIM was a predic-
\end{abstract}

Received January 31, 2013.

Accepted June 14, 2013.

${ }^{1}$ Corresponding author: w.heuwieser@fu-berlin.de tive cut point for primiparous cows to diagnose animals with or without SCE.

Key words: subclinical endometritis, $\alpha$-hemolytic streptococci, polymorphonuclear neutrophilic leukocyte cut point

\section{INTRODUCTION}

Different uterine diseases influence reproductive performance of dairy cows (Galvão et al., 2009). Subclinical (Sheldon et al., 2006) or cytological endometritis (Dubuc et al., 2010a) has a high prevalence but has been described controversially in the literature. Different approaches exist for diagnosing subclinical endometritis (SCE), considering a variety of postpartum intervals for sample collection and cut points (Table 1). All definitions include the absence of abnormal vaginal discharge, no clinical signs of illness, and increased PMNL percentages in the uterus (Kasimanickam et al., 2004; Sheldon et al., 2006). The applicability of ultrasonic findings of fluid-filled cavities over $0.2 \mathrm{~cm}$ in the uterus after 20 DIM was validated but the cytological method was proved to be more accurate (Lenz et al., 2007). Percentages of PMNL from 4 to $18 \%$ were used as cut points for the diagnosis of SCE in those studies. Furthermore, time of sampling for cytological diagnosis varied from 20 to $56 \mathrm{~d}$ postpartum. These differences impede the comparability of the results and the implementation of a consistent definition. Furthermore, it is unclear if the proportion of PMNL in the uterus fluctuates during the estrus cycle. In 2 older studies, increased PMNL percentages were found intra- and subepithelially around estrus in histological samples (Skjerven, 1956; Boos, 1981). These findings have not been confirmed in more recent studies using uterine lavage (Butt et al., 1991) or cytobrush techniques (Raab, 2004). Few studies investigated relationships between functional properties of PMNL and the diagnosis of SCE. Elevated NEFA concentrations had a negative effect on the myeloperoxidase activity of PMNL in the postpartum period (Hammon et al., 2006). Under the treatment with dexamethasone, the number of uterine PMNL increased, although the expression of adhesion 
Table 1. Summary of studies using the cytobrush technique to diagnose subclinical endometritis, considering time postpartum and thresholds for percentage of PMNL

\begin{tabular}{lccc}
\hline Reference & DIM $^{1}$ & PMNL (\%) & Prevalence (\%) \\
\hline Kasimanickam et al. (2004) & $20-33$ & $>18$ & 45 \\
Dubuc et al. (2010a) & $34-47$ & $>10$ & 41 \\
& $35 \pm 3$ & $\geq 6$ & 13.5 \\
Plöntzke et al. (2010) & $56 \pm 3$ & $>4$ & 9.6 \\
& $18-38$ & $>5$ & 19 \\
McDougall et al. (2011) & $32-52$ & $\geq 9$ & 29 \\
& $29 \pm 2.4$ & $\geq 7$ & 23 \\
\hline
\end{tabular}

${ }^{1}$ Cytological samples were collected during 2 periods postpartum.

${ }^{2}$ Mean \pm SD for DIM

molecules was decreased (König et al., 2006). So far, the effects of glucocorticoids have been interpreted as immunosuppressive (Reddy et al., 1990; Anderson et al., 1999).

Dubuc et al. (2010b) compared plausible risk factors for puerperal metritis, abnormal vaginal discharge, and cytological endometritis. Cows with a low BCS at parturition $(\leq 2.75)$, hyperketonemia $(\geq 1.1 \mu \mathrm{mol}$ of BHBA/L), or increased haptoglobin concentrations $(\geq 0.8 \mathrm{~g} / \mathrm{L})$ showed higher odds for SCE. These risk factors partly differed from the factors for puerperal metritis and abnormal vaginal discharge, which supports the hypothesis that these diseases are different manifestations in the uterus (Dubuc et al., 2010b). Agreements between the presence of uterine pathogens, such as Trueperella pyogenes, Fusobacterium necrophorum, Prevotella melaninogenica, Proteus spp., and Escherichia coli, and PMNL percentage on the same day postpartum (29 and 43 DIM) were only weak (McDougall et al., 2011). The presence of previous infections with recognized pathogens or opportunistic bacterial species, however, was not examined. Despite differences in sampling methods and times postpartum as well as different cut points for PMNL percentage, all studies demonstrated thresholds beyond which negative effects existed on reproductive performance [e.g., increased time to pregnancy (Galvão et al., 2009; Gilbert et al., 2005; Kasimanickam et al., 2004) and decreased conception rates (Kasimanickam et al., 2004; Kaufmann et al., 2009; McDougall et al., 2011)]. According to these findings, it is important to standardize the definition (i.e., cut point for PMNL percentage), time of sampling, and to elucidate the importance of previous infections as risk factors for SCE. The objective of this study was to determine the relationship between bacterial findings in the uterus and PMNL percentage in the early postpartum period. Specifically, for the first objective, we set out to test if previous or concurrent uterine infections with E. coli, T. pyogenes, Q-hemolytic streptococci (AHS) or CNS increase the risk for SCE after 20 DIM. For the second objective, we evaluated different cut points for the diagnosis of SCE.

\section{MATERIALS AND METHODS}

\section{Study Farm}

The study was conducted between September 2009 and August 2010 on a commercial dairy farm in Brandenburg, Germany. The herd consisted of 1,100 Holstein dairy cows with an average milk production of $9,831 \mathrm{~kg}$ per lactation (4.04\% fat and $3.31 \%$ protein). Cows were managed according to the guidelines set by the International Cooperation on Harmonisation of Technical Requirements for Registration of Veterinary Medicinal Products (Hellmann and Radeloff, 2000). The main barn was positioned in a northeast-southwest orientation with open ventilation and mechanical fans. Lactating cows were housed in freestall facilities with cubicles, rubber mats, and slotted floors, whereas dry cows were straw bedded. Early postpartum cows were fed a TMR consisting of $39.7 \%$ concentrate and mineral mix, $32.9 \%$ grass silage, and $19.2 \%$ corn silage $\left(\mathrm{NE}_{\mathrm{L}}\right.$ $=1.65 \mathrm{Mcal} / \mathrm{kg}$ ). Cows were milked 3 times per day (approximately at 0600, 1500, and $2200 \mathrm{~h}$ ). After calving, cows were assigned to a postpartum group and examined for clinical endometritis $(\mathbf{C E})$ by vaginal inspection with a speculum once between 21 and 27 DIM. The voluntary waiting period was 40 DIM. Cows were inseminated by an AI technician after a voluntary waiting period of 40 DIM. Cows with cystic ovarian disease or an extended calving-to-first conception interval (>150 DIM), or anovulatory cows (missing follicles or corpus luteum) were inseminated after an Ovsynch protocol.

\section{Study Design}

The farm was visited weekly to examine all cows at $10 \pm 1$ DIM (group A, exam 1). The same cows were 
reexamined at $24 \pm 1 \mathrm{DIM}$ (group A, exam 2). Cows were excluded from the study if CE (Sheldon et al., 2006) was diagnosed at $24 \pm 1$ DIM or if cows were treated with antibiotic, steroidal, or nonsteroidal antiinflammatory drugs since parturition. From 279 cows examined at $10 \pm 1$ DIM, 149 were included in the study after the second examination. The total number of cows examined and included was restricted by the investigation period from September 2009 until August 2010.

For the second objective, all cows at 21 to 27 DIM (group B) not affected with CE (Sheldon et al., 2006) were examined every week. It was documented if cows were treated with antibiotic drugs or nonsteroidal or steroidal antiinflammatory drugs since parturition. From 131 cows, cytobrush and bacteriological samples from the uterus could be collected.

Body temperature was measured with a digital thermometer (Burfeind et al., 2010) and body condition was scored on a 5-point scale in all cows of group A and B (Edmonson et al., 1989). Cows were classified in the BCS groups $<2.5,2.5$ to 3.5 , or $>3.5$. Vaginal examination in groups A (exam 2) and B was performed by vaginoscopy and vaginal discharge scored according to its distribution of clear mucus and pus. Vaginal discharge was scored from 0 to 3 as described by Williams et al. (2005): $0=$ clear mucus, $1=$ predominantly clear mucus containing flecks of pus, $2=$ mucopurulent mucus containing $\leq 50 \%$ pus, and $3=$ exudate containing purulent or red-brown material and (or) foul smelling. Cows were regarded as not affected with $\mathrm{CE}$ when diagnosed with a vaginal discharge score of 0 .

Cytological and bacteriological samples of the endometrial surface were collected in all 3 groups using the cytobrush technique as described previously (Kasimanickam et al., 2004). The brush (Cytobrush Plus GT, length $20 \mathrm{~mm}$, diameter $6 \mathrm{~mm}$; Precision Engineering Leisegang GmbH, Berlin, Germany) was covered by a one-way catheter, enveloped with a sanitary plastic sleeve, to protect it from contamination. After cleaning the vulva with dry cellulose wipes, the instrument was inserted via the cervix into the uterine body. Inside the uterus, the sleeve was retracted and the brush pushed gently into the lumen. The endometrial sample was taken by rolling the brush while in contact with the uterine wall. The brush was retracted into the catheter to protect it during the passage through the genital tract. Finally, the brush was rolled onto a sterile microscope slide and stored in a transport medium (UniTer Amies CLR; Meus s.r.l., Piove di Sacco, Italy) for bacteriological analysis. The slides were fixed on site and stained (LT-SYS, Haema-Schnellfärbung; Labor und Technik Eberhard Lehmann, Berlin, Germany) in the laboratory. The presence of PMNL and epithe- lial cells was examined with light microscopy (BHS microscope; Olympus, Hamburg, Germany) under oil immersion $(\times 1,000)$. A total of 300 cells were counted by 1 observer and the percentage of PMNL calculated. Two different classifications were statistically analyzed: PMNL $1(<5 \%, 5-18 \%$, and $>18 \%)$ and PMNL $2(<10 \%, 10-18 \%$, and $>18 \%)$. On every fourth farm visit, a cytobrush was unwrapped, dipped into sterile $\mathrm{NaCl}$, rolled on a sterile microscope slide and stored in a transport medium as negative control sample to analyze if the flora of the environment could influence the bacterial results.

Bacteriological samples were cultured for aerobic bacteria (E. coli, T. pyogenes, AHS, and CNS) on sheep blood agar and enriched in brain-heart infusion medium (Oxoid Ltd., Basingstoke, Hampshire, UK) and a standard nutrition I bouillon (Merck KGaA, Darmstadt, Germany) for $48 \mathrm{~h}$ at $37^{\circ} \mathrm{C}$. The broths were streaked onto sheep blood agar plates and cultured along with the other plates for a second time $24 \mathrm{~h}$ at $37^{\circ} \mathrm{C}$. Bacteria were identified on the basis of the characteristics of the colony, Gram stain, morphology, hemolysis, biochemical profile, and other standard tests, such as oxidase, catalase, and coagulase reaction and growth on MacConkey agar. Plates containing 1 or more colony-forming units were regarded as positive bacterial growth. Plates with more than 3 species or with mixed culture of moderate degree or higher were considered contaminated.

\section{Statistical Analysis}

Results of the vaginal and cytological examination, body temperature, BCS, and treatment were recorded on case report forms on farm and transferred into a spreadsheet (Microsoft Excel 2010; Microsoft Corp., Redmond, WA). Animal-specific data, treatments, and reproductive performance data were obtained from the herd management software and electronically transferred into the spreadsheet. Reproductive performance was characterized by days to first AI (DAI), days to pregnancy (DP), proportion of cows pregnant within 250 DIM (number of cows documented to be pregnant at 250 DIM divided by the number of cows enrolled $\times 100$ ), number of AI, and proportion of cows culled within 250 DIM. Data were analyzed using SPSS for Windows software (PASW Statistics 19.0; SPSS Inc., Munich, Germany) and MedCalc for Windows (MedCalc Software bvba, Ostend, Belgium). Bacterial findings and PMNL were analyzed with the Mann-Whitney $\mathrm{U}$ test and $t$-test for AHS. For the first objective, binary logistic regression was used: (1) PMNL percentage and cutoff at $18 \%$ PMNL for cows of group A with all covariates from $10 \pm 1$ DIM (BCS, parity, and positive 
Table 2. Frequency distribution of pathogens from cows examined at $10 \pm 1$ and $24 \pm 1$ DIM (group A) and cows examined once at 21 to 27 DIM (group B), considering body condition and parity

\begin{tabular}{|c|c|c|c|}
\hline \multirow[b]{2}{*}{ Variable $^{2}$} & \multicolumn{2}{|c|}{ Group A $(\mathrm{n}=142)$} & \multirow{2}{*}{$\frac{\text { Group B }(\mathrm{n}=126)}{21-27 \mathrm{DIM}}$} \\
\hline & $10 \pm 1 \mathrm{DIM}$ & $24 \pm 1 \mathrm{DIM}$ & \\
\hline No growth/mixed flora ${ }^{1}$ & 76 & 103 & 102 \\
\hline \multicolumn{4}{|l|}{ Pathogen } \\
\hline Escherichia coli positive & 25 & 14 & 12 \\
\hline Trueperella pyogenes positive & 7 & 4 & 2 \\
\hline AHS positive $^{2}$ & 34 & 14 & 7 \\
\hline CNS positive & 9 & 9 & 4 \\
\hline 2 Species & 9 & 2 & 1 \\
\hline \multicolumn{4}{|l|}{ BCS } \\
\hline$<2.5$ & 11 & 20 & 16 \\
\hline $2.5-3.5$ & 130 & 122 & 110 \\
\hline$>3.5$ & 1 & 0 & 0 \\
\hline \multicolumn{4}{|l|}{ Parity } \\
\hline Primiparous & 52 & & 53 \\
\hline Multiparous & 90 & & 73 \\
\hline \multicolumn{4}{|l|}{ PMNL $1(\%)$} \\
\hline$<5$ & & 99 & 99 \\
\hline $5-18$ & & 24 & 16 \\
\hline$>18$ & & 19 & 11 \\
\hline \multicolumn{4}{|l|}{ PMNL $2(\%)$} \\
\hline$<10$ & & 110 & 111 \\
\hline $10-18$ & & 13 & 4 \\
\hline$>18$ & & 19 & 11 \\
\hline
\end{tabular}

${ }^{1}$ No growth/mixed flora included samples with mixed cultures or without bacteriological findings.

${ }^{2} \mathrm{AHS}=\alpha$-hemolytic streptococci.

outcomes of E. coli, T. pyogenes, AHS, and CNS), (2) PMNL percentage and cutoff at $18 \%$ PMNL for cows of group A (exam 2) combined with group B with all covariates from $24 \pm 1$ and 21 to 27 DIM (BCS, parity, and positive outcomes of the 4 bacterial species), and (3) status of pregnancy at 250 DIM for cows of group A with the covariates as in (1) above. The effect of all bacterial findings on DAI and DP were calculated with survival analyses (Cox regression). For the second objective, receiver operating characteristic (ROC) curve analysis was used for (1) cows of group A (exam 2) combined with group B and (2) only primiparous cows of group A (exam 2) combined with primiparous cows of group B and the classification pregnancy. Survival analyses were used for the effect of PMNL groups (1 and 2) on DAI and DP. The level of significance for all analyses was $\alpha=0.05$. The confidence interval was set at $95 \%$.

\section{RESULTS}

Seven (4.7\%) out of 149 slides of group A (exam 1) could not be evaluated due to insufficient cellular material on the slide. The prevalence of bacteria from 142 cows for previous uterine infection was $25,7,34$, and 9 for E. coli, T. pyogenes, AHS, and CNS, respectively (Table 2). The numbers of cows classified into the 3 classes of PMNL 1 and PMNL 2 at $24 \pm 1$ DIM were
99, 24, and 19, and 110,13, and 19, respectively (Table 2 ). If 5,10 , or $18 \%$ PMNL were used as the cutoff for the diagnosis of SCE, the prevalence would be 30.3 , 22.6 , or $13.4 \%$, respectively. Mixed cultures or other species were found in $48.6 \%(\mathrm{n}=69)$ and $62 \%(\mathrm{n}=88)$ of the samples in group A (exam 1) and group A (exam 2 ), respectively. No bacterial growth was found in $4.9 \%$ $(\mathrm{n}=7)$ of group A (exam 1) and in $10.6 \%(\mathrm{n}=15)$ of group A (exam 2).

Of 131 cows in group B, 5 cows were excluded from analysis due to insufficient cellular material. For the calculation of concurrent uterine infection, 126 cows from group B were combined with 142 cows from group A (exam $2 ; \mathrm{n}=268)$. The prevalence of $E$. coli, $T$. pyogenes, AHS, and CNS was 26, 6, 21, and 13, respectively, at 21 to 27 DIM. The numbers of cows classified into the 3 classes of PMNL 1 and PMNL 2 were 198, 40 , and 30 , and 221, 17, and 30, respectively. Considering 5, 10, or $18 \%$ PMNL as the cut point for SCE, the prevalence was $26.1,17.5$, or $11.2 \%$, respectively. No bacterial growth and mixed cultures/other species were found in $12.7(\mathrm{n}=16)$ and $68.3 \%(\mathrm{n}=86)$, respectively, of group B.

For previous uterine infections of the first objective, we found significant effects for cows infected with AHS at $10 \pm 1$ DIM on PMNL percentage at $24 \pm 1$ DIM (Figure 1). Cows positive for AHS at $10 \pm 1$ DIM had greater DP compared with cows not infected with AHS 


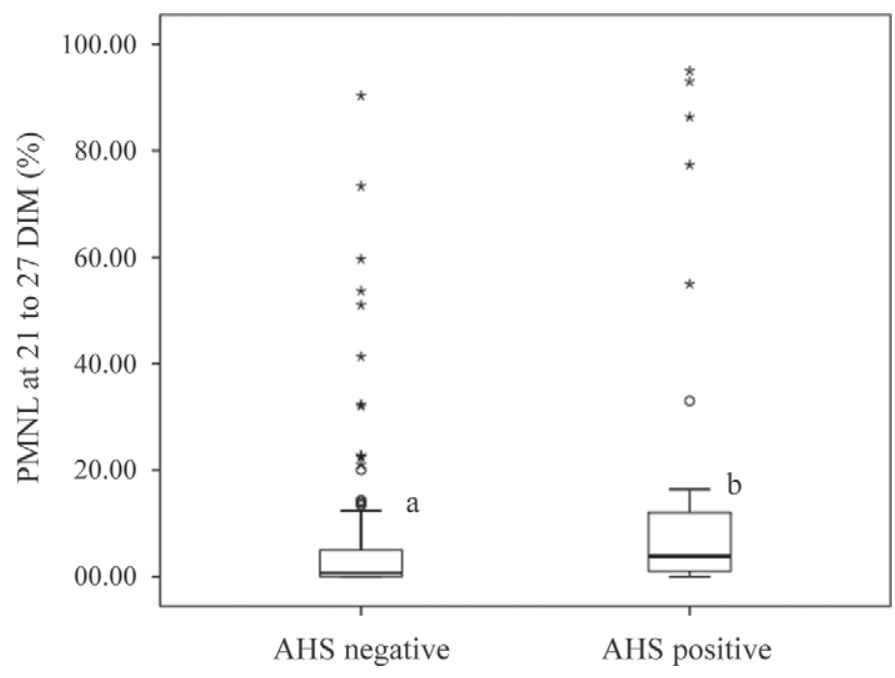

Figure 1. Box plot with the distribution of PMNL at $24 \pm 1$ DIM for cows positive and negative for $\alpha$-hemolytic streptococci (AHS) at $10 \pm 1$ DIM. The plots show the median (line within the box), 25th and 75 th percentiles (box), 5th and 95th percentiles (whiskers), and outliners (stars). a versus b: $P=0.006$.

(hazard ratio $=1.7 ; \mathrm{CI}=1.029-2.733 ; P=0.038)$ and decreased odds of pregnancy by 250 DIM (odds ratio $=$ 0.4 , CI $=0.164-0.870 ; P=0.022$; Table 3$)$. An infection with $T$. pyogenes at $10 \pm 1$ DIM increased the odds by 5.1 times of diagnosing the same cow with more than $18 \%$ PMNL $(P=0.046) 2$ wk later. The isolation of $E$. coli or CNS did not affect number of PMNL 2 wk later. Uterine pathogens isolated at 21 to 27 DIM did not affect the distribution of PMNL in PMNL 1 or PMNL 2 either. Body condition score group, parity, and treatment did not affect distribution of PMNL for either previous or current uterine infections.

For the second objective, all cows of group A (exam 2) were used for calculation. Reproductive performance parameters were similar in the different PMNL classes (Table 4). DP were numerically lower in cows of the intermediate PMNL classes (5-18\% and 10-18\%) compared with cows with $>18 \%$ PMNL (Table 4 ). Con-
Table 3. Reproductive performance of cows negative or positive with $\alpha$-hemolytic streptococci isolated from the uterus at $10 \pm 1$ DIM

\begin{tabular}{lcc}
\hline & \multicolumn{2}{c}{$\alpha$-Hemolytic streptococci } \\
\cline { 2 - 3 } Parameter & $\begin{array}{c}\text { Negative } \\
(\mathrm{n}=111)\end{array}$ & $\begin{array}{c}\text { Positive } \\
(\mathrm{n}=38)\end{array}$ \\
\hline Mean number of AI & 3.1 & 4.0 \\
Median days to first AI & 61 & 63.5 \\
Median days to pregnancy & $122^{\mathrm{a}}$ & $197.5^{\mathrm{b}}$ \\
Cows pregnant at 250 DIM (\%) & $78.7^{\mathrm{a}}$ & $58.8^{\mathrm{b}}$ \\
Cows culled (\%) & 6.5 & 5.9 \\
\hline a,b Means within a row with different superscripts differ $(P<0.05)$.
\end{tabular}

sidering parity, reproductive performance parameters in PMNL 1 and PMNL 2 differed. Primiparous cows with $>18 \%$ PMNL had significantly higher median DP $(144.5 \mathrm{~d}, \mathrm{SD}=91.9)$ than primiparous cows with $<5 \%$ PMNL ( $80 \mathrm{~d}, \mathrm{SD}=65.5 ; P=0.019)$ or cows with 5 to $18 \%$ PMNL ( $68 \mathrm{~d}, \mathrm{SD}=57.7 ; P=0.017$; Figure 2 ). A similar relationship existed for primiparous cows classified according to PMNL 2. Median DP were greater in cows with $>18 \%$ PMNL (144.5 d, SD = 91.9) compared with primiparous cows with $<10 \%$ PMNL $(77 \mathrm{~d}$, SD $=$ $64.9 ; P=0.017)$ or cows between 10 and $18 \%$ PMNL $(70 \mathrm{~d}, \mathrm{SD}=59.8 ; P=0.039)$. In multiparous cows, reproductive performance parameters did not significantly differ in PMNL 1 or PMNL 2. The distribution of E. coli, T. pyogenes, AHS, and CNS in PMNL 1 or PMNL 2 was similar in primiparous and multiparous cows.

\section{DISCUSSION}

The aim of this study was to examine the effect of aerobic bacterial infections in the uterus on PMNL and reproductive performance. Furthermore, 2 classification schemes for PMNL percentage were compared for the definition of SCE after 20 DIM.

Prevalence of SCE was lower compared with previous studies (Kasimanickam et al., 2004; Plöntzke et al., 2010; McDougall et al., 2011), irrespective of the

Table 4. Reproductive performance outcomes considering the 2 classification schemes for PMNL from cows of group A (second examination; $24 \pm 1$ DIM) combined with cows from group B (21-27 DIM)

\begin{tabular}{|c|c|c|c|c|c|c|}
\hline \multirow[b]{3}{*}{ Parameter } & \multicolumn{6}{|c|}{ Classification scheme } \\
\hline & \multicolumn{3}{|c|}{ PMNL $1(\%)$} & \multicolumn{3}{|c|}{ PMNL $2(\%)$} \\
\hline & $<5(\mathrm{n}=184)$ & $5-18(\mathrm{n}=34)$ & $>18(\mathrm{n}=25)$ & $<10(\mathrm{n}=203)$ & $10-18(\mathrm{n}=15)$ & $>18(\mathrm{n}=25)$ \\
\hline Mean number of AI & 3.5 & 3.1 & 3.9 & 3.4 & 3.3 & 3.9 \\
\hline Median days to first AI & 55 & 53.5 & 57 & 54 & 65 & 57 \\
\hline Median days to pregnancy & 107 & $79^{\mathrm{a}}$ & $120^{\mathrm{b}}$ & 105 & $98^{\mathrm{c}}$ & $120^{\mathrm{d}}$ \\
\hline Cows pregnant at 250 DIM (\%) & 72.2 & 71.8 & 58.6 & 71.4 & 82.4 & 58.6 \\
\hline Cows culled (\%) & 10.6 & 2.6 & 3.4 & 9.1 & 5.9 & 3.4 \\
\hline
\end{tabular}

\footnotetext{
${ }^{\mathrm{a}-\mathrm{d}}$ Means within a row with different superscripts differ numerically $\left({ }^{\mathrm{a} \text { vs. } \mathrm{b}} P=0.088 ;{ }^{\mathrm{c}}\right.$ vs. $\left.{ }^{\mathrm{d}} P=0.091\right)$.
} 


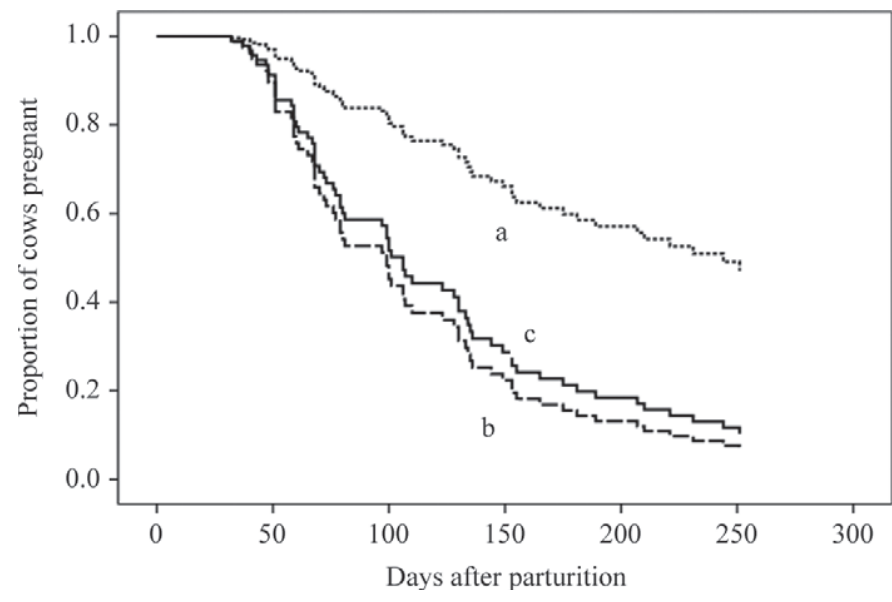

Figure 2. Survival curves for time to pregnancy up to $250 \mathrm{~d}$ postpartum of 106 primiparous cows considering 3 classes of PMNL: $<5 \%$ (continuous line), 5 to $18 \%$ (dashed line), and $>18 \%$ (dotted line). a versus b: $P=0.017$; a versus c: $P=0.019$.

classification scheme used. This finding could be due to a lower herd prevalence of SCE of the study site in the current study. Another factor could be the different number of cells counted per slide. Whereas we counted 300 cells per slide, previous authors counted 100 cells (Kasimanickam et al., 2004). We speculate that the larger number of cells counted reduced the probability of type 1 errors (i.e., cow diagnosed as SCE when actually healthy) because the diagnosis was less influenced by a positive count.

The lack of association between bacterial infections and presence of PMNL at the same examination day (i.e., 21 to 27 DIM) supports earlier findings that abnormal vaginal discharge is not necessarily indicative of endometrial inflammation (Dubuc et al., 2010a). The occurrence of abnormal discharge is associated with certain bacterial species, such as T. pyogenes, F. necrophorum, and Proteus spp. (Williams et al., 2005), which are known uterine pathogens, and AHS (Werner et al., 2012), which have been considered as opportunists until now. It is noteworthy that presence of AHS at $10 \pm 1$ DIM was associated with increased PMNL percentage at 21 to 27 DIM. Although previously shown that cows infected with AHS at $10 \pm 1$ DIM had higher risks for concurrent abnormal vaginal discharge (Werner et al., 2012), our data demonstrated that these animals also tended to have a higher risk for SCE in the fourth week postpartum. Until now, AHS were considered as opportunistic contaminants of the uterus (Williams et al., 2005). $\alpha$-Hemolytic streptococci were isolated in 28 of 34 samples (82.4\%) with high growth density (i.e., $>100$ colonies per plate) according to Williams et al. (2005). The high number of isolated bacteria may influence the immune system of the ani- mals and result in higher PMNL numbers. The effect of anaerobic uterine pathogens on PMNL percentage was not examined in this study and, thus, an effect on SCE cannot be excluded. McDougall et al. (2011), however, could not demonstrate any concurrent associations of known uterine pathogens including anaerobes (i.e., $E$. coli, T. pyogenes, F. necrophorum, Proteus spp., and P. melaninogenica) and PMNL percentage at 28 or at 42 DIM. Nevertheless, the effect of previous infections with anaerobic pathogens on PMNL percentage cannot be precluded due to insufficient studies and should be further researched. Furthermore, our results provide the first evidence that DP and cumulative number of cows pregnant can be negatively affected by the presence of AHS compared with healthy cows. Our finding that early uterine infections with AHS are associated with higher PMNL percentage and lower reproductive performance confirms the pathogenic character of AHS, which warrants further research.

Escherichia coli was isolated in 25 cows at $10 \pm 1$ DIM. The lack of association between an infection with E. coli and abnormal vaginal discharge (Williams et al., 2005; Werner et al., 2012) and their induced depression of neutrophils (Zerbe et al., 2001) may confirm an association with SCE. No association was found between $E$. coli infection and SCE in our study; however, $E$. coli infection occurred in 15 of 25 samples (60\%) with high growth density. Trueperella pyogenes was isolated in few samples $(n=7)$ but with high growth density in all but one of them. Trueperella pyogenes is strongly associated with abnormal vaginal discharge, and such cows were excluded from the study. Nevertheless, an effect on SCE could be proved. An infection with $T$. pyogenes is potentially attributed to the impairment of the endometrium induced by other pathogens (Williams et al., 2007; Werner et al., 2012). This stimulus for the immune system and the synergistic effect on gram-negative anaerobes such as $F$. necrophorum and $P$. melaninogenica (Williams et al. 2005; Földi et al., 2006) could explain the persisting high counts of PMNL. The low numbers of samples positive with CNS, particularly with high growth density $(2 / 9)$, indicate that an effect on SCE did not exist in our study. No study exists describing any pathogenic character of this bacterial species.

Regarding the outcomes of mixed cultures or other bacterial species, we speculate that contamination with environmental bacteria occurred during sampling or rolling the cytobrush on the microscope slide. None of the 11 negative control samples, however, showed contamination with E. coli, T. pyogenes, or CNS. In 4 samples, mixed cultures were isolated, one that had 1 Acinetobacter species and 1 sample that was positive for AHS. 
Variation in cut points used in the literature to distinguish SCE cows from healthy cows is wide and precludes a consistent diagnosis. Also, the collection times vary widely. We speculate that the latter might influence the number of PMNL, as elevated NEFA due to negative energy balance affect PMNL activity (Hammon et al., 2006). Also, functionality of blood PMNL decreased around parturition and returned only to normal around 4 wk postpartum (Kehrli et al., 1989). Due to fact that the uterus is normally contaminated after parturition with different bacteria (Bondurant, 1999; Földi et al., 2006; Sheldon et al., 2008), the response of the immune system with PMNL is important. The health and metabolic status of the cow might influence this reaction and consequently the reproductive performance, which could explain the effects in our PMNL classes. Furthermore, König et al. (2006) showed that after the treatment of cows with dexamethasone, the adhesion molecule L-selectin on the PMNL surface was downregulated. This molecule is important for margination and emigration of PMNL from blood into the tissue and the uterine lumen. Despite the reduced expression, a higher number of PMNL migrated into the uterine lumen mediated by human IL-8, compared with cows treated with the placebo (König et al., 2006). In stress situations (e.g., group or ration changes and hoof trimming), blood cortisol could have the same effect and lead to a stronger immune response and consequently more PMNL in the uterine lumen. These observations can help to explain the higher reproductive performance (DAI and DP) of cows in PMNL classes 5 to 18 and 10 to $18 \%$ compared with cows with a lower or higher PMNL percentage in this study.

Differences between primiparous and multiparous cows have been described in previous studies. For primiparous cows, similar associations between PMNL group $(0,0-15$, or $>15 \%)$ and lower odds for pregnancy in the low- and high-PMNL group compared with the medium group existed at the time of insemination (Kaufmann et al., 2009). Higher odds for SCE were found in primiparous cows with high milk production (Cheong et al., 2011) but they did not find differences in reproductive performance between primiparous cows with and without SCE. The missing effect on reproductive performance compared with our results could have been caused by the different time of examination and different cutoff points for the diagnosis of SCE. Furthermore, interventions after the second sample may have influenced reproductive performance. Considering these and our findings, we propose that plausible risk factors for SCE should be analyzed for primiparous and multiparous cows separately. Our data provide further evidence that the cut point of $18 \%$ PMNL at 20 to 30
DIM as described by (Kasimanickam et al., 2004) is adequate to diagnose SCE, at least in primiparous cows.

\section{CONCLUSIONS}

Our results demonstrate that a uterine infection with AHS at $10 \pm 1$ DIM is a relevant risk factor for the emergence of high PMNL percentage at 21 to 27 DIM. Furthermore, AHS-infected cows had longer intervals to pregnancy and a lower likelihood of getting pregnant. An infection with $T$. pyogenes at $10 \pm 1$ DIM increased the risk of diagnosing the same cow with SCE 2 wk later. Infections with $E$. coli or CNS did not affect the prevalence of SCE. A cut point of $18 \%$ PMNL at 21 to 27 DIM had a high diagnostic value for distinguishing cows with or without SCE, especially in primiparous cows. In this study, cows with $>18 \%$ PMNL showed the worst reproductive performance parameters compared with cows with 5 to 18 or 10 to $18 \%$ PMNL, and those with $<5$ or $<10 \%$ PMNL.

\section{ACKNOWLEDGMENTS}

The authors thank the owners and staff of the dairy farm for their superb cooperation and all practitioners involved in the trial for their valuable assistance. Additionally, we would thank the staff of the Clinic for Animal Reproduction, Freie Universität Berlin (Berlin, Germany) for the important ideas and help in statistical analysis.

\section{REFERENCES}

Anderson, B. H., D. L. Watson, and I. G. Colditz. 1999. The effect of dexamethasone on some immunological parameters in cattle. Vet. Res. Commun. 23:399-413.

Bondurant, R. H. 1999. Inflammation in the bovine female reproductive tract. J. Anim. Sci. 77(Suppl. 2):101-110.

Boos, A. 1981. Histomorphologische Veränderungen im Endometrium des Rindes während der verschiedenen Zyklusphasen. University of Hannover. Doctoral Diss. University of Hannover, Hannover, Germany.

Burfeind, O., M. A. von Keyserlingk, D. M. Weary, D. M. Veira, and W. Heuwieser. 2010. Short communication: Repeatability of measures of rectal temperature in dairy cows. J. Dairy Sci. 93:624627.

Butt, B. M., P. L. Senger, and P. R. Widders. 1991. Neutrophil migration into the bovine uterine lumen following intrauterine inoculation with killed Haemophilus somnus. J. Reprod. Fertil. 93:341-345.

Cheong, S. H., D. V. Nydam, K. N. Galvão, B. M. Crosier, and R. O. Gilbert. 2011. Cow-level and herd-level risk factors for subclinical endometritis in lactating Holstein cows. J. Dairy Sci. 94:762-770.

Dubuc, J., T. F. Duffield, K. E. Leslie, J. S. Walton, and S. J. LeBlanc. 2010a. Definitions and diagnosis of postpartum endometritis in dairy cows. J. Dairy Sci. 93:5225-5233.

Dubuc, J., T. F. Duffield, K. E. Leslie, J. S. Walton, and S. J. LeBlanc. 2010b. Risk factors for postpartum uterine diseases in dairy cows. J. Dairy Sci. 93:5764-5771. 
Edmonson, A. J., I. J. Lean, L. D. Weaver, T. Farver, and G. Webster. 1989. A body condition scoring chart for Holstein dairy cows. J. Dairy Sci. 72:68-78.

Földi, J., M. Kulcsár, A. Pécsi, B. Huyghe, C. de Sa, J. A. C. M. Lohuis, P. Cox, and G. Huszenicza. 2006. Bacterial complications of postpartum uterine involution in cattle. Anim. Reprod. Sci. 96:265-281.

Galvão, K. N., M. Frajblat, S. B. Brittin, W. R. Butler, C. L. Guard, and R. O. Gilbert. 2009. Effect of prostaglandin $F_{2 \alpha}$ on subclinical endometritis and fertility in dairy cows. J. Dairy Sci. 92:49064913.

Gilbert, R. O., S. T. Shin, C. L. Guard, H. N. Erb, and M. Frajblat. 2005. Prevalence of endometritis and its effects on reproductive performance of dairy cows. Theriogenology 64:1879-1888.

Hammon, D. S., I. M. Evjen, T. R. Dhiman, J. P. Goff, and J. L. Walters. 2006. Neutrophil function and energy status in Holstein cows with uterine health disorders. Vet. Immunol. Immunopathol. $113: 21-29$.

Hellmann, K., and I. Radeloff. 2000. International Cooperation on Harmonisation of Technical Requirements for Registration of Veterinary Medicinal Products. VICH, Brussels, Belgium.

Kasimanickam, R., T. F. Duffield, R. A. Foster, C. J. Gartley, K. E. Leslie, J. S. Walton, and W. H. Johnson. 2004. Endometrial cytology and ultrasonography for the detection of subclinical endometritis in postpartum dairy cows. Theriogenology 62:9-23.

Kaufmann, T. B., M. Drillich, B. A. Tenhagen, D. Forderung, and W. Heuwieser. 2009. Prevalence of bovine subclinical endometritis $4 \mathrm{~h}$ after insemination and its effects on first service conception rate. Theriogenology 71:385-391.

Kehrli, M. E., Jr., B. J. Nonnecke, and J. A. Roth. 1989. Alterations in bovine neutrophil function during the periparturient period. Am. J. Vet. Res. 50:207-214.

König, T., H. J. Schuberth, W. Leibold, and H. Zerbe. 2006. Dexamethasone depresses the expression of L-selectin but not the in vivo migration of bovine neutrophils into the uterus. Theriogenology 65:1227-1241.

Lenz, M., M. Drillich, and W. Heuwieser. 2007. Evaluation of the diagnosis of subclinical endometritis in dairy cattle using ultrasound. Berl. Munch. Tierärztl. Wochenschr. 120:237-244. (In German.)

McDougall, S., H. Hussein, D. Aberdein, K. Buckle, J. Roche, C. Burke, M. Mitchell, and S. Meier. 2011. Relationships between cy- tology, bacteriology and vaginal discharge scores and reproductive performance in dairy cattle. Theriogenology 76:229-240.

Plöntzke, J., L. V. Madoz, R. L. De la Sota, M. Drillich, and W. Heuwieser. 2010. Subclinical endometritis and its impact on reproductive performance in grazing dairy cattle in Argentina. Anim. Reprod. Sci. 122:52-57.

Raab, D. 2004. Evaluierung der Cytobrush-Methode zur Diagnostik von subklinischen Endometritiden und Auswirkungen der Entzündung auf die folgende Fruchtbarkeitsleistung von Milchkühen. Mensch \& Buch Verlag, Berlin, Germany.

Reddy, P. G.. D. S. McVey, M. M. Chengappa, F. Blecha, H. C. Minocha, and P. E. Baker. 1990. Bovine recombinant granulocytemacrophage colony-stimulating factor enhancement of bovine neutrophil functions in vitro. Am. J. Vet. Res. 51:1395-1399.

Sheldon, I. M., G. S. Lewis, S. LeBlanc, and R. O. Gilbert. 2006. Defining postpartum uterine disease in cattle. Theriogenology 65:1516-1530

Sheldon, I. M., E. J. Williams, A. N. Miller, D. M. Nash, and S. Herath. 2008. Uterine diseases in cattle after parturition. Vet. J 176:115-121.

Skjerven, O. 1956. Endometrial biopsy studies in reproductively normal cattle; clinical, histochemical and histological observations during the estrous cycle. Acta Endocrinol. Suppl. (Copenh.) 22(Suppl. 26):1-101.

Werner, A., V. Suthar, J. Plöntzke, and W. Heuwieser. 2012. Relationship between bacteriological findings in the second and fourth weeks postpartum and uterine infection in dairy cows considering bacteriological results. J. Dairy Sci. 95:7105-7114.

Williams, E. J., D. P. Fischer, D. E. Noakes, G. C. England, A. Rycroft, H. Dobson, and I. M. Sheldon. 2007. The relationship between uterine pathogen growth density and ovarian function in the postpartum dairy cow. Theriogenology 68:549-559.

Williams, E. J., D. P. Fischer, D. U. Pfeiffer, G. C. England, D. E. Noakes, H. Dobson, and I. M. Sheldon. 2005. Clinical evaluation of postpartum vaginal mucus reflects uterine bacterial infection and the immune response in cattle. Theriogenology 63:102-117.

Zerbe, H., C. Oßadnik, W. Leibold, and H. J. Schuberth. 2001. Influence of Escherichia coli and Arcanobacterium pyogenes isolated from bovine puerperal uteri on phenotypic and functional properties of neutrophils. Vet. Microbiol. 79:351-365. 